\title{
Quantifying the Stability of Trace Explosives under Different Environmental Conditions using Electrospray Ionization Mass Spectrometry
}

\author{
Edward Sisco ${ }^{a \star}$, Marcela Najarro ${ }^{a}$, Daniel Samarov ${ }^{b}$, and Jeffrey Lawrence ${ }^{a}$ \\ ${ }^{a}$ National Institute of Standards and Technology, Materials Measurement Science Division, \\ Gaithersburg, MD, USA \\ ${ }^{b}$ National Institute of Standards and Technology, Statistical Engineering Division, Gaithersburg, \\ MD, USA \\ *Correspondence: edward.sisco@nist.gov \\ $\dagger$ Official contribution of the National Institute of Standards and Technology; not subject to \\ copyright in the United States
}

\begin{abstract}
This work investigates the stability of trace (tens of nanograms) deposits of six explosives: erythritol tetranitrate (ETN), pentaerythritol tetranitrate (PETN), cyclotrimethylenetrinitramine (RDX), cyclotetramethylenetetranitramine (HMX), 2,4,6-trinitrotoluene (TNT), and 2,4,6trinitrophenylmethylnitramine (tetryl) to determine environmental stabilities and lifetimes of trace level materials. Explosives were inkjet printed directly onto substrates and exposed to one of seven environmental conditions (Laboratory, $-4{ }^{\circ} \mathrm{C}, 30^{\circ} \mathrm{C}, 47^{\circ} \mathrm{C}, 90 \%$ relative humidity, UVlight, and ozone) up to 42 days. Throughout the study, samples were extracted and quantified using electrospray ionization mass spectrometry (ESI-MS) to determine the stability of the explosive as a function of time and environmental exposure. Statistical models were then fit to the data and used for pairwise comparisons of the environments. Stability was found to be exposure and compound dependent with minimal sample losses observed for HMX, RDX, and PETN while substantial and rapid losses wereobserved in all conditions except $-4{ }^{\circ} \mathrm{Cfor}$ ETN and TNT and in all conditions for tetryl. The results of this work highlight the potential fate of explosive traces when exposed to various environments.
\end{abstract}

Keywords: Trace Explosives; Mass Spectrometry; Degradation; Environmental Stability

Page 1 of 16

(C) 2016. This manuscript version is made available under the Elsevier user license 


\section{Introduction}

Forensic examiners, crime scene technicians, and military personnel rely on the ability to harvest post-blast explosive residue from debris for the identification of the source of material used in a terrorist or criminal event. The chemical analysis of post-blast material can provide information regarding the manufacturing process (military vs. homemade), contaminants, and/or chemical markers.[1-3]Taggant identification can determine the origin of the explosive (manufacturer and batch number) and provide a list of the last legal purchasers of the material.[4]Also, terrorist organizations from a particular geographic region may have a preference for a specific homemade explosive formulation, which could be discerned from postblast analysis.[5-7]Identification of the materials' origin can be critical to an investigation since it can link a perpetrator to the crime scene through source attribution. However, the remote location of many explosions or terrorist eventscan delay the collection and analysis time for post-blast residues.

In the pre-collection interval, the explosive residue is exposed to a variety of environmental conditions that may induce physical and chemical changes. The probability of recovery and detection will depend on the environmental conditions at the scene, the length of exposure, and the storage conditions of evidence after collection. Physical evidence processing may take place on site using field-deployed trace detection equipment,[8,9] canines,[10,11] and/or chemical tests. Samples may also be collected and preserved for analysis in a laboratory. Laboratory-based analysis has been documented to identify the type of explosive from post-blast residues approximately $50 \%$ of the time; the manufacturer can be identified less than $10 \%$ of the time.[4]In addition to post-blast analysis, determination of the environmental stability of trace explosives can aid in establishing the length of time a residue will remain on a surface after being used to synthesize homemade explosives or after being contaminated by someone whose hands contain trace residues.

Most degradation research has focused on the detection and bioavailability of bulk material for remediation efforts of ordinance sites. Knowledge of the time-dependent loss and transformation of trace explosive residue could help forensic examiners interpret the absence of a positive identification of an explosive at a crime scene. Currently, there is limited literature on the fate of trace (nanogram quantities) explosive residues as a function of time orenvironment.

Kunz et al.have studied explosive degradation in the trace to bulk region and have estimated the lifetimes of 2,4,6-trinitrotoluene (TNT), hexahydro 1,3,5-trinitro-1,3,5-triazine (RDX) and pentaerythritol tetranitrate (PETN) for outdoor stand-off optical detection.[12]A recent study was published regarding the effect of a saline environment on the degradation of 
RDX and TNT.[13] This study found explosives in saltwater were relatively stable, however, UV exposure caused rapid degradation of both RDX and TNT.

The present work addresses the question of trace explosive residue persistence by quantitativelymeasuring the temporal decay rate of trace explosive residue as a function of temperature, humidity, ozone, and UV light.Inkjet-printed trace explosives residues were aged up to six weeks and then extracted and quantified using electrospray ionization mass spectrometry (ESI-MS). Statistical analysis was then completed to construct models to fit the decays and to evaluate commonalities and differences between different environments using pairwise comparisons. This paper provides a model to predict the viability of trace explosives residues. In addition, recommendations for storage conditions are suggested. Future work will focus on the characterization of degradation products that may help improve detection algorithms based on known chemical changes to the material.

\section{Materials and Methods}

\section{Materials \&Inkjet Printing}

Inkjet printing was used to deposithighly reproducible (<3\% RSD)[14] trace amounts (tens of nanograms) of explosives from standard solutions onto polytetrafluoroethylene (PTFE) -coated fiberglass substrates (Multi-Purpose Sample Traps (part: ST1318), DSA Detection, North Andover, MA, USA) *.PTFE-coated substrates were chosen for their chemical inertness and use as a collection media for trace explosive residues in security screening situations (i.e. airports or federal buildings). Six explosives were characterized and included: erythritol tetranitrate $(\mathrm{ETN})$, pentaerythritol tetranitrate (PETN), cyclotrimethylenetrinitramine (RDX), cyclotetramethylenetetranitramine $\quad(H M X), \quad 2,4,6$-trinitrotoluene $\quad$ (TNT), and 2,4,6trinitrophenylmethylnitramine (tetryl). Additional details regarding the parameters used to create the samples can be found in the Supplemental Information.Once samples were created they were stored in plastic trays lined with aluminum foil and openly exposed to one of the seven environments.

\section{Environmental Exposure}

To capture diverse environments, seven different environmental exposures were simulated, includinglow temperature $\left(-4{ }^{\circ} \mathrm{C}\right)$, heat $\left(30^{\circ} \mathrm{C}\right)$, extreme heat $\left(47^{\circ} \mathrm{C}\right)$, elevated ozone $\left(\mathrm{O}_{3}\right)$, simulated UV exposure (UV), and elevated humidity (90\% RH). Ambient laboratory (Lab)conditions were also employed to monitor changes in a laboratory microclimate. Lab samples were left on a laboratory bench at $23{ }^{\circ} \mathrm{C}\left( \pm 1{ }^{\circ} \mathrm{C}\right)$ and $22 \%$ relative humidity $(\mathrm{RH})$. To 
simulatecold climates and demonstrate the effect of freezer storage, $-4{ }^{\circ} \mathrm{C}\left( \pm 2{ }^{\circ} \mathrm{C}\right.$ and $\left.23 \% \mathrm{RH}\right)$ samples were placed inside a standard laboratory freezer (Cole-Parmer, Vernon Hills, IL., USA). An elevated temperature to mimic a temperate summer, $30{ }^{\circ} \mathrm{C}\left( \pm 2{ }^{\circ} \mathrm{C}\right.$ and $\left.23 \% \mathrm{RH}\right)$, and a desert summer, $47^{\circ} \mathrm{C}\left( \pm 1{ }^{\circ} \mathrm{C}\right.$ and $\left.22 \% \mathrm{RH}\right)$ were simulated byplacing samples inside separate laboratory ovens (Thermo Scientific, Waltham, MA, USA). Additionally, the $30^{\circ} \mathrm{C}$ exposure was used to drawcomparisons to the UV and $90 \% \mathrm{RH}$ exposures, also kept at $30{ }^{\circ} \mathrm{C}$. Exposure to sunlight was simulated with controlled exposure of samples to UV by placing them under a 5 lamp exposure panel containing one UVB lamp (centered at $300 \mathrm{~nm}$ ) and four UVA lamps (centered at $350 \mathrm{~nm}$ ) (Luzchem Research, Gloucester, ON, CA). Approximately twenty-four hours of exposure under the panel equated to 12 hours of sun exposure at the equator. The temperature under the panels reached approximately $30{ }^{\circ} \mathrm{C}$ and the relative humidity was $23 \%$. For $90 \% \mathrm{RH}$, which simulated exposure in a tropical environment, samples were placed inside a humidity controlled chamber (Weather-ometer, Associated Environmental System, Ayer, MA, USA) setto90 \%( $\pm 2 \% \mathrm{RH})$ and $30{ }^{\circ} \mathrm{C}\left( \pm 1{ }^{\circ} \mathrm{C}\right)$. Finally, high ozone levels in an urban environment were simulated by placing samples inside a chamber containing an ozone generator (Jenesco, Amherst, NH, USA). The ozone generator provided a pulsed introduction of ozone, for one minute every ninety-nine minutes, allowing minimal buildup of ozone concentrations. The average ozone concentration measured by an ozone monitor (Aeroqual Series 500 Monitor, Aeroqual Limited, Auckland, NZ),was 0.2 ppm, approximately twice the ozone level in an urban environment (0.1 ppm)[15] but the lowest level obtainable using this configuration. All samples were continually exposed to their respective environments until removed for analysis. Three samples and a substrate blank were removed for extraction after $(0,1,3,7,10,14,21,28,35$, and 42$)$ days.Baseline (day 0$)$ samples were also run.

\section{Sample Extraction\& ESI-MS Analysis}

For analysis and quantification by ESI-MS, PTFE -coated fiberglass substrates containing the explosive were trimmed to a dimension of approximately $1.5 \mathrm{~cm}$ by $2 \mathrm{~cm}$ and placed into a 1.5 $\mathrm{mL}$ amber glass vial. One $\mathrm{mL}$ of methanol (Chromasolv grade, Sigma-Aldrich, St. Louis, MO, USA) containing the appropriate internal standard (Table 1) was added to the vial, capped, and vortexed for $30 \mathrm{~s}$ at 10,000 rotations $\mathrm{s}^{-1}$. The solution was then directly injected into the ESIMS. Extraction efficiencies off of the PTFE swipes were measured by inkjet printing botha known mass of explosive onto the swipe and directly into a $1.5 \mathrm{~mL}$ amber glass vial. The swipe was extracted while the sample in the glass vial was reconstituted in methanol containing internal standard, and the two concentrations were compared. The extraction efficiencies were 
found to exceed $98.0 \%$ for all cases, with a range of extraction efficiencies from $98.0 \%-99.6$ $\%$.

Quantification was completed using a JEOL JMS-T100LP AccuTOF ${ }^{\circledR}$ mass spectrometer (JEOL USA, Peabody, MA, USA) coupled with the manufacturer's electrospray source. The mobile phase, $100 \%$ methanol at a flow rate of $0.25 \mathrm{~mL} \mathrm{~min}^{-1}$, was introduced using a Varian ProStar pump (Agilent, Santa Clara, CA, USA) and passed through a Rheodyne (Oakharbor, WA, USA) manual injection valve equipped with a $5 \mu \mathrm{L}$ sample loop. All samples were injected in triplicate. Mass spectrometer parameters for the quantification scans included: negative polarity, $-2000 \mathrm{~V}$ needle voltage, $-20 \mathrm{~V}$ first orifice voltage, $-5 \mathrm{~V}$ second orifice voltage, $-5 \mathrm{~V}$ ring voltage, $100{ }^{\circ} \mathrm{C}$ orifice temperature, and $250{ }^{\circ} \mathrm{C}$ desolvating chamber temperature through which zero-air nitrogen was used as both the nebulizing and desolvating gas. Mass scan ranges were explosive-specific and corresponded to the base peak of the respective analyte and internal standard (Table 1).An internal standard blank,a substrate blank, and a calibration verification sample were also run with each analysis to ensure the stability of the internal standard and calibration curve as well as monitor the background. The substrate blanks were used to ensure background compounds were not overlapping with the peaks of interest. The internal standard blanks were used to ensure stability of the internal standard and identify whether or not it was contributing to the overall quantified mass of any explosive. The calibration verification samples were present at approximately the same concentration as the baseline samples and used to adjust the quantified masses on a given day by accounting for slight variations from the calibration curve. The relative standard deviations from the gravimetric concentration for the calibration verification samples was consistently less than $5 \% \mathrm{RSD}$ for all explosives.

Quantification of samples was completed by taking the ratio of the explosive to the internal standard and comparing the ratio to a calibration curve. The eight-point calibration curves (Figure S1) were created gravimetrically and spanned the range of $1 \mathrm{ngmL}^{-1}$ to $50 \mathrm{ngmL}^{-}$

1. Three samples from every time point and environmental exposure were completed in this manner with the exception of the day zero time-point, where six samples were analyzed. The data represents a total of nine data points (3 replicates at 3 injections per replicate). Uncertainty is reported as one standard deviation of this sample set.

\section{Statistical Treatment of Data}

To model decay rates, an exponential model of the following form was used: 


$$
f(t)=a_{0}+a \times \exp (-b t), b \geq 0(\text { Eqn. } 1)
$$

The observed data was taken to be $y(t)=f(t)+\epsilon(t)$, where errors $\epsilon(t)$ were assumed to be independently and identically distributed with mean 0 and standard deviation $\sigma$. Note, in the actual model fitting procedure we take $b=\exp \left(b_{0}\right)$ and solve for $b_{0}$ to ensure that $b \geq 0$.

For each explosive type and environmental factor, denoted by indices $i$ and $j$ respectively, a non-linear least squares model was fitted to estimate the initial quantity parameter $a_{i j}$ and decay rate $b_{i j}$. The decay rate was parameterizedas $b=\exp \left(b_{i j}^{*}\right)$, to satisfy the positivity constraint and ensure monotonicity of the model as the quantity of explosive can only decrease over time $t$. Using the decay estimates $\hat{b}_{i j}^{*}$ and their associated variance estimates $\operatorname{var}\left(\hat{b}_{i j}^{*}\right)$ pairwise comparisons between each environmental factor for each type of explosive were performed. Specifically, the test statistic was:

$$
c_{j k}(i)=\frac{\hat{b}_{i j}^{*}-\hat{b}_{i k}^{*}}{\left[\frac{\operatorname{var}\left(\hat{b}_{i j}^{*}\right)}{2}+\frac{\operatorname{var}\left(\hat{b}_{i k}^{*}\right)}{2}\right]^{\frac{1}{2}}}(\text { Eqn. 2) }
$$

Similar calculations were performed from the baseline decay level $\left(a_{0}\right)$, and the steady state amount(a). With seven environmental factors this resulted in 21 pairwise comparisons for each parameter $\left(a, a_{0}\right.$, and $\left.b\right)$ for each type of explosive. The value of $c_{j k}(i)$ was compared against a $t$ distribution with degrees of freedom (df), corresponding to the number of replicate measurements. The resulting $p$-values were adjusted for multiple comparisons using the Benjamini-Hochberg procedure for false discovery rate (FDR) corrections.[16]The assessment of differences between decay rates was performed by looking at the pairwise difference between all three model parameters, e.g. $a_{0}$ (Condition1) versus $a_{0}$ (Condition2), a(Condition1) versus $a$ (Condition2), and $b$ (Condition1) versus $b$ (Condition2). Summary data of these comparisons are presented in subsequent figures and in-depth data regarding these comparisons can be found in the Supplemental Information.

\section{Results and Discussion}

Nitrate Esters - PETN \& ETN

The stability of ETN and PETN are shown in Figure 1 (A, B, D, and E). While structurally similar, ETN has a vapor pressure approximatelyfour orders of magnitude[17] higher than PETN. With the exception of $-4{ }^{\circ} \mathrm{C}$ storage, the mass of ETN present was found to decrease by more than $50 \%$ within the first three days. Stability of ETN at $-4{ }^{\circ} \mathrm{C}$ was greatest, with $76 \%$ of ETN remaining on the swipe after 42 days. All other conditions exhibited rapid loss of ETN,including Lab samples, where an $80 \%$ decrease in mass was observed over the first three 
days.Because ETN was stable at $-4{ }^{\circ} \mathrm{C}$, but rapidly decayed under Lab conditions, where decomposition of the molecule by chemical or photochemical means was unlikely, the main pathway for ETN loss is believed to be through sublimation. Exposures where chemical decomposition was more likely to occur ( $\mathrm{UV}, 90 \% \mathrm{RH}$, and $\mathrm{O}_{3}$ ) exhibited a greater rate of degradation than $\mathrm{Lab}$ and $30{ }^{\circ} \mathrm{C}$ exposures, indicating additional decomposition pathwaysmay be occurring under these conditions.

Little research exists on the degradation of trace $(<100 \mathrm{ng})$ or bulk $(>1 \mu \mathrm{g})$ ETN to determine if the trends observed with trace amounts correlate to bulk material or post blast. Based on the data shown in Figure 1 (A \& B) collection of trace explosives off of a surface believed to contain ETN would need to occur within the first day to maximize the chances of recovery and detection. Furthermore, storage of samples in any condition other than a freezer would likely lead to rapid sublimation of ETN, lowering the probability of detection.Since sublimation may be playing a significant role in the loss of ETN off of a surface, additional research is required to understand the role of both particle size and initial starting mass on the loss of ETN.

To determine if there was a statistically significant change in the quantity of explosive between Day 0 and Day 42, a Student's $t$-test (95\% confidence interval) was completed for each exposure, comparing the average explosive mass at the beginning to the end of the study (Table S3). It was found that the remaining mass of ETN present at Day 42 was statistically different for all storage conditions.

Figure 1Cshowsa color-coded matrix of $p$-values for the pairwise comparisons of the decay rates $\left(b_{i j}\right)$ and the steady state amount $\left(a_{0}\right)$ obtained from each of the 42-day exposure conditions for ETN.The comparison of the magnitude of the decay parameter (a) is not included as it is an artifact of the model fit. Boxes containing an " $X$ " represent comparisons where there was a statistically significant difference $(p<0.05)$ between either the decay rate (blue), steady state amount (yellow), or both (green). Boxes without an "X" show comparisons whereboth the decay rate and steady state amountwere not statistically different. Some measurements, such as $-4{ }^{\circ} \mathrm{C}$ for ETN, had a high degree of variability which potentially masked statistical differences between these and other decay rates and may not be properly represented. Therefore, more comparisons could be statistically different if the variation was lowered.Conditions where this occurred were identified by models with $\mathrm{p}$-values greater than 0.05 for all model fit parameters (Tables S4, S5, and S6).

Comparison of the $a_{0}$ and $b$ terms shows that nearly all of the conditions were statistically different. Ozone and $90 \% \mathrm{RH}$ exhibited no statistical difference in either termand 
was represented by the rapid loss of ETN under both conditions (Figure 1B). Similarly, a difference only in the $b$ term was observed in UV and Ozone indicating that the steady state amount was not different (both conditions reached unquantifiable levels), but the rate at which this level wasreached were different. Many of the other comparisons highlight the difference in the steady state term ( $a_{0}$, yellow) as the main contribution to the differences observed, indicating that rates of decayacross many conditions were similar. It should be noted that the p-value of the $b$ term for $-4{ }^{\circ} \mathrm{C}$ was greater than 0.05 , indicating that not all $b$ terms which were statistically different to $-4{ }^{\circ} \mathrm{C}$ may be represented (Figure S2). Several other conditions (Ozone:Lab, UV:30 ${ }^{\circ} \mathrm{C}, \mathrm{UV}: 90 \% \mathrm{RH}$, and UV: $47^{\circ} \mathrm{C}$ ) were observed to have statistical differences in both the $\mathrm{a}_{0}$ and $b$ terms. UV comparisons to most conditions showed a rate of decay statistically different, indicating that photolysis may be a major contributor to losses observed under UV.

PETN exhibited notably greater stability across all environmental conditions compared to ETN. As with ETN, less than $20 \%$ loss of PETN occurred when exposed to $-4{ }^{\circ} \mathrm{C}$ conditions (Figure 1D). No condition exhibited greater than $50 \%$ loss until at least Day 7, while Lab and $\mathrm{O}_{3}$ exposures exhibitedat least50 \% retention for the duration of the study. Losses of PETN under the Labenvironment were about $50 \%$ less than ETN, and approximately $10 \%$ less at 47 ${ }^{\circ} \mathrm{C}$ - attributable to the lower volatility and thus decreased sublimation rates ofPETN.

Though stability was generally higher for PETN than ETN, substantialPETN losseswere still observeddue to exposure toUV, elevated temperature, and elevated humidity. Exposure to UV caused complete loss of quantifiable material by Day 28. Degradation of bulk PETN in the presence of UV light has been previously reported and has been proposed as a mechanism for remediation of contaminated surfaces and soils.[18,19]UV photo-decomposition has also been employed to enhance the detection of PETN offsurfacesfrom standoff (> $10 \mathrm{~m}$ ) distances.[20] Ozonolysis of PETN has not been previously reported under the conditions studied, and may have a minorcontribution to the near $50 \%$ loss observed in the $\mathrm{O}_{3}$ environment (when $\mathrm{O}_{3}$ and Lab conditions were compared). Hydrolysis of PETN, which likely caused the increased losses observed under $90 \% \mathrm{RH}$ conditions, has been reported to occur within hours of exposure as PETN is hydrolyzed into a number of compounds including pentaerythritol trinitrate, pentaerythritoldinitrate, pentaerythritolmononitrate, and pentaerythritol.[21]Unfortunately, the mass scan range used in this work did not allow for identification of these compounds in the samples and is the focus of current work.

Because of the 4 orders of magnitude lower volatility of PETN, collection and recovery of this explosive off of a surface after prolonged times is more probable than ETN. Recovery of a significant amount (>50\%) of the initial trace may be possible for weeks unless elevated 
temperatures, excessive humidity, or UV light are present, under which useful collection may be limited to several days. It is important to note that this study only accounts for specific environmental exposures. More complex exposures, meteorological phenomena (wind, rain, snow, etc.) and other relevant parameters (particle size, deposition surface, number of particles, presence of background chemicals) may alter these stabilities significantly. Storage of these PETN-containing materials under Lab conditions should be sufficient in the short term, though storage at $-4{ }^{\circ} \mathrm{C}$ will help preserve the material.

Statistical analysis of the data using the Student's $t$-test showed a significant difference between the initial and final mass for all exposure conditions except $-4{ }^{\circ} \mathrm{C}$ (Table S3). The pairwise comparisonsof exposure conditions (Figure 1F)highlighted a significant difference in either the decay rate, steady state amount, or both, for all comparisons except $30^{\circ} \mathrm{C}$. All terms for the $30^{\circ} \mathrm{C}$ model had p-values greater than 0.05 (Tables S4, S5, and S6), which contributed to the lack of statistical difference when compared to other exposures. Exposure to $-4{ }^{\circ} \mathrm{C}$ showed a statistically significant difference in the steady state, much like ETN, indicating that storage in a freezer will help prevent additional losses. Comparison of the lab and ozone conditions indicates a difference in the decay rate but not in the steady state, showing that losses occurred more rapidly under ozone exposure, though absolute losses were not different than Lab. Similarly, for $47^{\circ} \mathrm{C}$ and $90 \% \mathrm{RH}$ a more rapid loss was observed for 47 ${ }^{\circ} \mathrm{C}$.Comparisons where both terms were found to be statistically differentwere mainly focused on comparisons to $47^{\circ} \mathrm{C}$ and UV. The rapid loss of PETN under UV, was confirmed by the large degree of differences observed when compared to other conditions. Elevated temperature caused a rapid loss as well, as sublimation of the material was enhanced.

\section{Nitramines - RDX \& HMX}

The impact of environmental exposures onRDX \& HMX was less dramatic than what was experienced by other explosives. RDX (Figure 2A and $2 \mathrm{~B}$ ) showed a slower rate of decay than both PETN and ETN under the conditions examined, with the exception of UV exposure. Though degradationoccurred at a slower rate, greater than $50 \%$ loss wasobserved for four out of the seven exposures(UV, $47^{\circ} \mathrm{C}, 90 \% \mathrm{RH}$, and $\left.30{ }^{\circ} \mathrm{C}\right)$ over the 42 -day period. The least stable exposure condition was simulated UV, where the explosive rapidly decomposed, degrading to unquantifiable levels by Day 10. Lack of stability of RDX under UV light has been reported in previous work[12,22] where RDXwas shown to rapidly degrade into small volatile compounds such as $\mathrm{NO}, \mathrm{CO}, \mathrm{N}_{2}, \mathrm{CH}_{4}, \mathrm{H}_{2}$, and others.[12] The quantitative losses observed in our study for UV exposure agreed with those described by Kunz et al who proposed that loss of 
RDX was rapidin the presence of sunlight. Other exposures relatable to that study(namely Lab and $-4{ }^{\circ} \mathrm{C}$ ) exhibited similar losses (49 \% and $18 \%$ loss over 42 days, respectively). Interestingly, RDX appearsmore stable in the presence of $\mathrm{O}_{3}$ than PETN and ETN, potentially due to a combination of lower volatility and lower reactivity. Prior work has shown that degradation of RDX through ozonolysis is slower thanphoto-degradation, though the two exposures have a synergistic effect in accelerated degradation together.[23]Modification of the surface through ozonolysis may also play a role and is being investigated.

Statistical comparison of the initial and final mass of RDX present across exposures, using the Student's $t$-test showed a significant difference in all conditions. The pairwise comparisons of decay curves and steady state amounts across the environmental conditions (Figure 2C) indicated that nearly all environmental conditions caused decay at different rates (blue or green boxes).No difference was observed between ozone and $30{ }^{\circ}$ Chighlighting the minimal impact of elevated levels of ozone. UV exposure caused the greatest degradation of RDX and was different from all conditions except $-4{ }^{\circ} \mathrm{C}$ in both rate and steady state amount which exhibited a similar rate but different steady state amount. The difference in $30{ }^{\circ} \mathrm{C}$ and 90 $\% \mathrm{RH}$ was only in the decay term, indicating that though the elevated humidity will speed up the rate of RDX degradation it will not cause a greater loss of RDX. Based on the greater stability of RDX, recovery of RDX traces under real world conditions would likely have a higher probability of being detected weeks after deposition, with the exception of UV exposure, which exhibited rapid loss in material. It is important to note with RDX, and all explosives, that analysis was completed using pure explosive.The presence of binders, plasticizers, and UV stabilizers inplastic bonded explosives such as C4, Semtex, or Detasheet may significantly alter the stability of these compounds.

$\mathrm{HMX}$ was the most stable compound studied (Figure 2D and 2E). Across the 42-day study, less than $40 \%$ loss in masswas observed forall exposures, except UV light which, like RDX, caused rapid loss of the explosive over the first ten days. Rapid decomposition of bulk HMX under UV exposure has been previous reported in aqueous solutions, where complete loss was seen in a matter of hours.[24] As with RDX, HMX appeared to be minimallyaffected byexposure $\mathrm{toO}_{3}$ or elevated humidity. $\mathrm{HMX}$ was the least volatile compound studied, showing minimal thermal dependence on stability and high retention across the temperatures studied, due to minimal sublimation.

Student's $t$-test comparisons of initial and final masses found a statistically significant difference for all conditions. Pairwise comparisons of the decay rates (Figure 2F) highlighted the greater loss of HMX under UVexposurewith the exception of ozone, which had a high 
degree of variability (Table S4, S5, and S6). The model for ozone had p-values greater than 0.05 for both the $a_{0}$ and $b$ terms. No difference was found between Lab and $30{ }^{\circ} \mathrm{C}$ exposure, indicating slightly elevated temperatures were not detrimental to the stability of the explosive. Exposure to $-4{ }^{\circ} \mathrm{C}$ was also found to be different, though to a lesser degree (as evidenced with lower $p$-values and dissimilar $a_{0}$ values) from other exposures with the exception of $47^{\circ} \mathrm{C}$ and $90 \% \mathrm{RH}$, who shared similar decay rates. It was unclear why the steady state levels of $-4{ }^{\circ} \mathrm{C}$, $47^{\circ} \mathrm{C}$, and $90 \%$ RHwere similar but different from Lab or $30^{\circ} \mathrm{C}$ conditions. Similar steady state levels were also observed for $90 \% \mathrm{RH}$ and $47{ }^{\circ} \mathrm{C}$, indicating equal mass losses over time. Recovery of traces of HMX under outdoor conditions exposed to sunlight (UV) may be limited to days, however, if shielded from sunlight, HMX should be recoverable for weeks regardless of other environmental conditions. For the storage of materialsbelieved to contain traces of either $\mathrm{RDX}$ or $\mathrm{HMX}$ it is not necessary they are stored under low temperatures, as would be necessary for ETN.

\section{Nitroaromatics - TNT \& Tetryl}

The stability of nitroaromatic explosives exhibited similar trends to the nitrate esters. For TNT (Figure 3A and 3B), one of the most commonly studied explosives in terms of degradation, exhibited rapid loss of explosive across all conditions except $-4{ }^{\circ} \mathrm{C}$. Stability under $-4{ }^{\circ} \mathrm{C}$ was excellent, with approximately 10 \% loss in mass observed during the 42-day study, however, variation in the measurement was high, potentially due to absorption of water in the freezer environment. Exposure to Lab conditions exhibited approximately $50 \%$ loss in mass over the study, with nearly all losses occurring during the first seven days. The rapid loss was followed by leveling outcould be attributed to sublimation of the explosive followed by the formation of a degradation product which creates a shell around the particle.[12] The degradation productthat has been proposed isa dimerized species which has a lower vapor pressure than TNT.[12] Across the other temperatures similar phenomena were observed, though with a greater initial degradation than under Lab conditions.

Degradation of TNT by UVlight has been reported in the past.[13,24-26] Stability of TNT under UV lightinghas been shown to be short lived as it is photodegraded into a compound that produces the characteristic orange-red color.[13]At the trace levels studied here, TNT was undetectable after 14 days of exposure, which was shorter than other work has reported,[13] but attributable to the lower initial mass (tens of nanograms) of TNT. A similarly rapid rate of degradation was observed under $\mathrm{O}_{3}$ exposure, where TNT was unquantifiableafter 14 days as 
well. TNT degradation via ozonolysis has been previously reported for remediation efforts[27] though not discussed in terms of environmental exposure.

Statistical comparisons of the initial and final masses of TNT, using Student's $t$-tests showed significant losses under all conditions except $-4{ }^{\circ} \mathrm{C}$ (Table S3). Much like ETN, it is crucial to store samples believed to contain TNT under decreased temperatures to minimize the rate of sublimation, which was substantial even under Lab conditions. However, due to high variability in the TNT $-4{ }^{\circ} \mathrm{C}$ samples, the p-value for all three of the model's terms was greater than 0.05 , limiting pairwise comparisons. Pairwise comparisons of the decay rates (Figure $3 \mathrm{C}$ ) highlighted similar decay rates and steady state levels for $30{ }^{\circ} \mathrm{C}$ and ozone and at least one difference $\left(a_{0}\right.$ or $\left.b\right)$ for all other comparisons (except $-4{ }^{\circ} \mathrm{C}$ which had high variability). Both ozone and $30^{\circ} \mathrm{C}$ had different, slower, decay rates than any other condition. Thoughthe decay rates were statistically different, the lifetime of TNT under most environmental conditions was short-lived, emphasizing the need to rapidly collect and analyzesamples of interest. Under most conditions, trace TNT samples not collected within a week may be undetectable.

Tetryl was found to behave similarly to TNT (Figure 3D and 3E). Exposure to UV and $\mathrm{O}_{3}$ presented rapid losses, with unquantifiable amounts present after 10 days of exposure to $\mathrm{O}_{3}$. UV exposure never caused complete loss of material, but levels were reduced by more than 50 $\%$ over the first week. Though little literature exists on the environmental degradation of tetryl, one study has shown enhanced degradation occurs with UVlight during remediation efforts. [28]A high thermal effect on the stability of tetryl was also exhibited, with elevated temperatures causing nearly complete loss of material after three weeks of exposure. Losses at lower temperatures $\left(30^{\circ} \mathrm{C}\right.$, Lab, and $-4{ }^{\circ} \mathrm{C}$ ) were also observed, but were significantly lower in magnitude (approximately $50 \%$ to $60 \%$ ). It was unclear why tetryl exhibited the lower stability under storage at $-4{ }^{\circ} \mathrm{C}$ compared to Lab conditions, and future work is focused on identifying the cause(s).

Statistical analysis of the initial and final masses of tetryl present, using the Student's $t$ test, showed significant loss occurred under all conditions. Pairwise comparisons of the decay rates (Figure 3F) were confounded by high variation amongst the measurements, which was noticed in all conditions except UV. Remaining conditions had high p-values for either the $a_{0}$ or $b$ terms, and both $30{ }^{\circ} \mathrm{C}$ and $90 \% \mathrm{RH}$ had high values for both terms. One potential reason for increased variation was that the [M-NO]fragment was monitored for quantification due to its abundance, though it could have also been a decomposition product. The characteristic curve for the UV exposure was differentiable from all other conditions through the decay rate.Regardless of the environment, collection of tetryl off of a surface would need to occur 
rapidly in order to maintain the best chances for collection. Once collected, analysis would need to be done quickly to ensure the highest probability of detection, as even under decreased temperatures, loss of tetryl occurs.A different representation of the data by showing direct comparisons of the explosives under all environmental conditions is shown in Figure S8.

\section{Conclusion}

Trace amounts of six explosives were prepared using inkjet printing, exposed to one of seven different environmental conditions, and aged. Samples were quantified using ESI-MS and decay rates of the explosives under different conditions were modeled and compared using pairwise comparisons. Under UV conditions, all compounds exhibited near complete loss of material by the end of the study, with rapid losses being observed during the first seven days. $\mathrm{O}_{3}$ proved to be most detrimental to nitrate ester and nitroaromatic explosives. Decays were typically least pronounced in the nitramines.Volatile compounds such as ETN and TNT, exhibited rapid losses across the temperature range studied, except for $-4{ }^{\circ} \mathrm{C}$, the condition for which all but tetryl exhibited the greatest stability. These results provide a basis for what types of degradation should be expected when explosives traces are recovered from blast or crime scenes and stored for subsequent analysis. Storage at lower temperatures $\left(-4^{\circ} \mathrm{C}\right)$ would likely be best for the preservation of evidence thought to contain explosive material. When collecting evidence from a scene with harsh environmental conditions (elevated temperature, UV exposure) trace residues more than several days old may no longer be detectable.

It is important to note that this study represented ideal situations and does not account for other factors that may also affect residue loss, such as surface type, contaminations, other weather related events (wind, rain, etc.), or the presence of binders and plasticizers, which are common in military grade explosives. Future work will investigate some of these variables as well as attempt to identify degradation products and pathways responsible for the losses observed in this work. Future work is also looking at the formation of the trace residues formed by inkjet printing to determine their comparability to pre- and post-blast residues.

\section{Acknowledgements}

This work was partially supported by the Department of Homeland Security (DHS) Science and Technology Directorate, under Interagency Agreement HSHQPM-14-X-00098 with NIST. 


\section{References}

[1] A. Banas, K. Banas, M. Bahou, H.O. Moser, L. Wen, P. Yang, Z.J. Li, M. Cholewa, S.K. Lim, C.H. Lim, Post-blast detection of traces of explosives by means of Fourier transform infrared spectroscopy, Vibrational Spectroscopy. 51 (2009) 168-176. doi:10.1016/j.vibspec.2009.04.003.

[2] A.T. Quirk, J.M. Bellerby, J.F. Carter, F.A. Thomas, J.C. Hill, An initial evaluation of stable isotopic characterisation of post-blast plastic debris from improvised explosive devices, Science \& Justice. 49 (2009) 87-93. doi:10.1016/j.scijus.2009.02.009.

[3] D.D. Garner, M.L. Fultz, E.B. Byall, The ATF approach to post-blast explosives detection and identification, Journal of Energetic Materials. 4 (1986) 133-148. doi:10.1080/07370658608011337.

[4] Taggants in explosives., DIANE Publishing, 1980.

[5] S.J. Benson, C.J. Lennard, P. Maynard, D.M. Hill, A.S. Andrew, C. Roux, Forensic analysis of explosives using isotope ratio mass spectrometry (IRMS) - Preliminary study on TATP and PETN, Science \& Justice. 49 (2009) 81-86. doi:10.1016/j.scijus.2009.03.004.

[6] C. Johns, R.A. Shellie, O.G. Potter, J.W. O'Reilly, J.P. Hutchinson, R.M. Guijt, M.C. Breadmore, E.F. Hilder, G.W. Dicinoski, P.R. Haddad, Identification of homemade inorganic explosives by ion chromatographic analysis of post-blast residues, Journal of Chromatography A. 1182 (2008) 205-214. doi:10.1016/j.chroma.2008.01.014.

[7] M. Kotrlý, I. Turková, Analysis of nonstandard and home-made explosives and post-blast residues in forensic practice, in: 2014: p. 90730U-90730U-10. doi:10.1117/12.2050121.

[8] D.D. Fetterolf, Detection of Trace Explosive Evidence by Ion Mobility Spectrometry, in: J. Yinon (Ed.), Advances in Analysis and Detection of Explosives, Springer Netherlands, Dordrecht, 1993: pp. 117-131. http://link.springer.com/10.1007/978-94-017-0639-1_13 (accessed October 19, 2015).

[9] On-site Rapid Detection of Trace Non-volatile Inorganic Explosives by Stand-alone Ion Mobility Spectrometry via Acid-enhanced Evaporization : Scientific Reports, (n.d.). http://www.nature.com/articles/srep06631 (accessed June 20, 2016).

[10] M. Marshall, J.C. Oxley, Aspects of Explosives Detection, Elsevier, 2011.

[11] K.G. Furton, L.J. Myers, The scientific foundation and efficacy of the use of canines as chemical detectors for explosives, Talanta. 54 (2001) 487-500. doi:10.1016/S00399140(00)00546-4.

[12] R.R. Kunz, K.E. Gregory, M.J. Aernecke, M.L. Clark, A. Ostrinskaya, A.W. Fountain, Fate Dynamics of Environmentally Exposed Explosive Traces, J. Phys. Chem. A. 116 (2012) 3611-3624. doi:10.1021/jp211260t.

[13] E. Sisco, M. Najarro, C. Bridge, R. Aranda, Quantifying the degradation of TNT and RDX in a saline environment with and without UV-exposure, Forensic Science International. 251 (2015) 124-131. doi:10.1016/j.forsciint.2015.04.002. 
[14] R.M. Verkouteren, J.R. Verkouteren, Inkjet Metrology: High-Accuracy Mass Measurements of Microdroplets Produced by a Drop-on-Demand Dispenser, Anal Chem. 81 (2009) 85778584. doi:10.1021/ac901563j.

[15] F.J. Miller, J.W. Illing, D.E. Gardner, Effect of urban ozone levels on laboratory-induced respiratory infections, Toxicology Letters. 2 (1978) 163-169. doi:10.1016/03784274(78)90091-7.

[16] Y. Benjamini, D. Yekutieli, The Control of the False Discovery Rate in Multiple Testing under Dependency, The Annals of Statistics. 29 (2001) 1165-1188.

[17] O. US EPA, EPI Suite ${ }^{\mathrm{TM}}$-Estimation Program Interface, (n.d.). https://www.epa.gov/tscascreening-tools/epi-suitetm-estimation-program-interface (accessed May 5, 2016).

[18] L.M. Ballesteros-Rueda, G.M. Herrera-Sandoval, N. Mina, M.E. Castro-Rosario, J.G. Briano, S.P. Hernandez-Rivera, Spectroscopic signatures of PETN: Part II. Detection in clay, in: 2006: p. 62173D-62173D-8. doi:10.1117/12.666539.

[19] H. Giefers, M. Pravica, Radiation-Induced Decomposition of PETN and TATB under Extreme Conditions, J. Phys. Chem. A. 112 (2008) 3352-3359. doi:10.1021/jp710512b.

[20] M.E. Morales-Rodríguez, C.W. Van Neste, L.R. Senesac, S.M. Mahajan, T. Thundat, Ultra violet decomposition of surface adsorbed explosives investigated with infrared standoff spectroscopy, Sensors and Actuators B: Chemical. 161 (2012) 961-966. doi:10.1016/j.snb.2011.11.073.

[21] F.J. DiCarlo, J.M. Hartigan, G.E. Phillips, Analysis of Pentaerythritol Tetranitrate and Its Hydrolysis Products by Thin Layer Chromatography and Radio Scanning., Anal. Chem. 36 (1964) 2301-2303. doi:10.1021/ac60218a024.

[22] P. Bose, W.H. Glaze, D.S. Maddox, Degradation of RDX by various advanced oxidation processes: I. Reaction rates, Water Research. 32 (1998) 997-1004. doi:10.1016/S00431354(97)00307-2.

[23] A.F. Smetana, S. Bulusu, Photochemical Studies of Secondary Nitramines. Part 2. Ultraviolet Photolysis and Ozonolysis of RDX in Aqueous Solutions, 1977.

[24] C.C. Andrews, J.L. Osmon, The Effects of UV Light on TNT and Other Explosives in Aqueous Solution, 1977.

[25] D.C. Schmelling, K.A. Gray, P.V. Kamat, Role of Reduction in the Photocatalytic Degradation of TNT, Environ. Sci. Technol. 30 (1996) 2547-2555. doi:10.1021/es950896l.

[26] H.-S. Son, S.-J. Lee, I.-H. Cho, K.-D. Zoh, Kinetics and mechanism of TNT degradation in TiO2 photocatalysis, Chemosphere. 57 (2004) 309-317. doi:10.1016/j.chemosphere.2004.05.008.

[27] P.S. Lang, W.-K. Ching, D.M. Willberg, M.R. Hoffmann, Oxidative Degradation of 2,4,6Trinitrotoluene by Ozone in an Electrohydraulic Discharge Reactor, Environ. Sci. Technol. 32 (1998) 3142-3148. doi:10.1021/es980052c.

[28] M.-J. Liou, M.-C. Lu, J.-N. Chen, Oxidation of explosives by Fenton and photo-Fenton processes, Water Research. 37 (2003) 3172-3179. doi:10.1016/S0043-1354(03)00158-1.

\section{Captions}

Table 1. Instrumental parameters and internal standards used for quantification of trace explosive residues by ESI-MS. i-RDX $\left({ }^{13} \mathrm{C}_{3},{ }^{15} \mathrm{~N}_{3}\right)$ and i-TNT $\left({ }^{13} \mathrm{C}_{7},{ }^{15} \mathrm{~N}_{3}\right)$ indicate isotopically tagged explosives purchased as $1.0 \mathrm{mg} \mathrm{mL}^{-1}$ solutions (Cambridge Isotopes, Tewksbury, MA, USA).

aVapor pressures ("VP", mmHg at $25^{\circ} \mathrm{C}$ ) were obtained from "EPI Suite v4.11". [US EPA. [2014]. Estimation Programs Interface Suite ${ }^{\mathrm{TM}}$ for Microsoft ${ }^{\circledR}$ Windows, $v$ 4.11]. All vapor pressures are the experimental vapor pressures except those with an asterisk $\left(^{*}\right)$ which are the estimated vapor pressures. 
Figure 1. Stability curves for ETN (A. and B.) and PETN (D. and E.) for each of the seven environmental conditions. Error bars represent the standard deviation of the triplicate measurements of the three samples analyzed at each time point. Lines represent the curves fit to the data and used for pairwise comparisons. The pairwise comparisons of the $a_{0}$ and $b$ terms of the decay rates are also shown for ETN (C.) and PETN (F.) to illustrate which conditions exhibited statistically significant differences (colored boxes with an " $X$ "). Individual plots for each term and a list of $p$-values for the pairwise comparisons of all terms $\left(a, a_{0}\right.$, and $\left.b\right)$ can be found in the Supplemental Information (Tables S7 and S8 as well as Figure S2 and S3).

Figure 2. Stability curves for RDX (A. and B.) and HMX (D. and E.) for each of the seven environmental conditions. Error bars represent the standard deviation of the triplicate measurements of the three samples analyzed at each time point. Lines represent the curves fit to the data and used for pairwise comparisons. The pairwise comparisons of the $a_{0}$ and $b$ term of the decay rates are also shown for RDX (C.) and HMX (F.) to illustrate which conditions exhibited statistically significant differences (colored boxes with an "X"). Individual plots for each terms and a list of $p$-values for the pairwise comparisons of all terms $\left(a, a_{0}\right.$, and $b$ ) can be found in the Supplemental Information (Tables S9 and S10 as well as Figure S4 and S5).

Figure 3. Stability curves for TNT (A. and B.) and tetryl (D. and E.) for each of the seven environmental conditions. Error bars represent the standard deviation of the triplicate measurements of the three samples analyzed at each time point. Lines represent the curves fit to the data and used for pairwise comparisons. The pairwise comparisons of the $a_{0}$ and $b$ terms of the decay rates are also shown for TNT (C.) and tetryl (F.) to illustrate which conditions exhibited statistically significant differences (colored boxes with an "X"). Individual plots for each term and a list of $p$-values for the pairwise comparisons of all terms $\left(a, a_{0}\right.$, and $\left.b\right)$ can be found in the Supplemental Information (Tables S11 and S12 as well as Figure S6 and S7). 


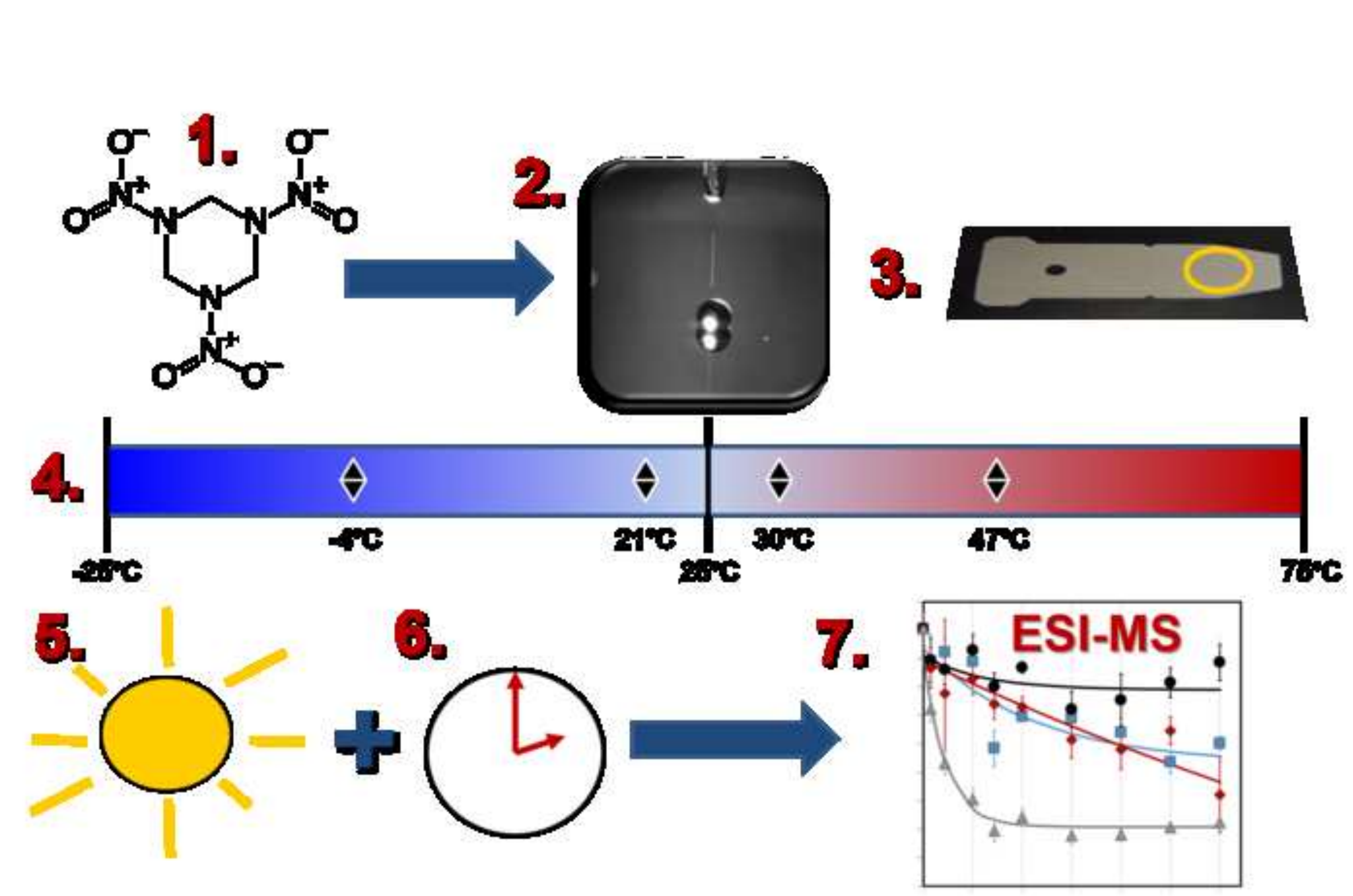




\begin{tabular}{|c|c|c|c|c|c|c|}
\hline $\begin{array}{c}\text { Explosiv } \\
e\end{array}$ & $\begin{array}{l}\text { Vapor } \\
\text { Pressur } \\
\text { e (kPa) }\end{array}$ & $\begin{array}{c}\text { Internal } \\
\text { Standar } \\
\text { d }\end{array}$ & $\begin{array}{c}\text { Explosive } \\
\text { Signal } \\
\text { Monitore } \\
\text { d }(m / z)\end{array}$ & $\begin{array}{c}\text { Internal } \\
\text { Standard } \\
\text { Signal } \\
\text { Monitore } \\
d(m / z)\end{array}$ & $\begin{array}{c}\text { Mass } \\
\text { Spectra } \\
I \\
\text { Window } \\
(\boldsymbol{m} / \mathbf{z})\end{array}$ & $\begin{array}{c}\text { LOD }_{90}(\% \\
\text { Relative to } \\
\text { Initial } \\
\text { Concentration }\end{array}$ \\
\hline RDX & $\begin{array}{c}5.58 \times 10^{-} \\
10\end{array}$ & i-RDX & $\begin{array}{c}284 \\
{\left[\mathrm{M}+\mathrm{NO}_{3}\right]^{-}}\end{array}$ & $\begin{array}{c}290 \\
{\left[\mathrm{M}+\mathrm{NO}_{3}\right]^{-}}\end{array}$ & $\begin{array}{l}260- \\
310\end{array}$ & 2.59 \\
\hline HMX & $4.40 \times 10^{-}$ & i-RDX & $\begin{array}{c}358 \\
{\left[\mathrm{M}+\mathrm{NO}_{3}\right]^{-}}\end{array}$ & $\begin{array}{c}290 \\
{\left[\mathrm{M}+\mathrm{NO}_{3}\right]^{-}}\end{array}$ & $\begin{array}{c}280- \\
360 \\
\end{array}$ & 6.64 \\
\hline PETN & $\underset{10}{7.27 \times 10^{-}}$ & ETN & $\begin{array}{c}378 \\
{\left[\mathrm{M}+\mathrm{NO}_{3}\right]^{-}}\end{array}$ & $\begin{array}{c}364 \\
{\left[\mathrm{M}+\mathrm{NO}_{3}\right]^{-}}\end{array}$ & $\begin{array}{c}350- \\
400\end{array}$ & 5.07 \\
\hline ETN & $8.19 \times 10^{-}$ & PETN & $\begin{array}{c}364 \\
{\left[\mathrm{M}+\mathrm{NO}_{3}\right]^{-}}\end{array}$ & $\begin{array}{c}378 \\
{\left[\mathrm{M}+\mathrm{NO}_{3}\right]^{-}}\end{array}$ & $\begin{array}{c}350- \\
400\end{array}$ & 1.21 \\
\hline TNT & $1.07 \times 10^{-6}$ & i-TNT & $226[\mathrm{M}-\mathrm{H}]^{-}$ & $236[\mathrm{M}-\mathrm{H}]^{-}$ & $\begin{array}{l}200- \\
250\end{array}$ & 6.56 \\
\hline Tetryl & $\underset{8 *}{1.56 \times 10^{-}}$ & i-TNT & $\begin{array}{c}241[\mathrm{M}- \\
\left.\mathrm{NO}_{2}\right]^{-}\end{array}$ & $236[\mathrm{M}-\mathrm{H}]^{-}$ & $\begin{array}{l}220- \\
270\end{array}$ & 10.3 \\
\hline
\end{tabular}



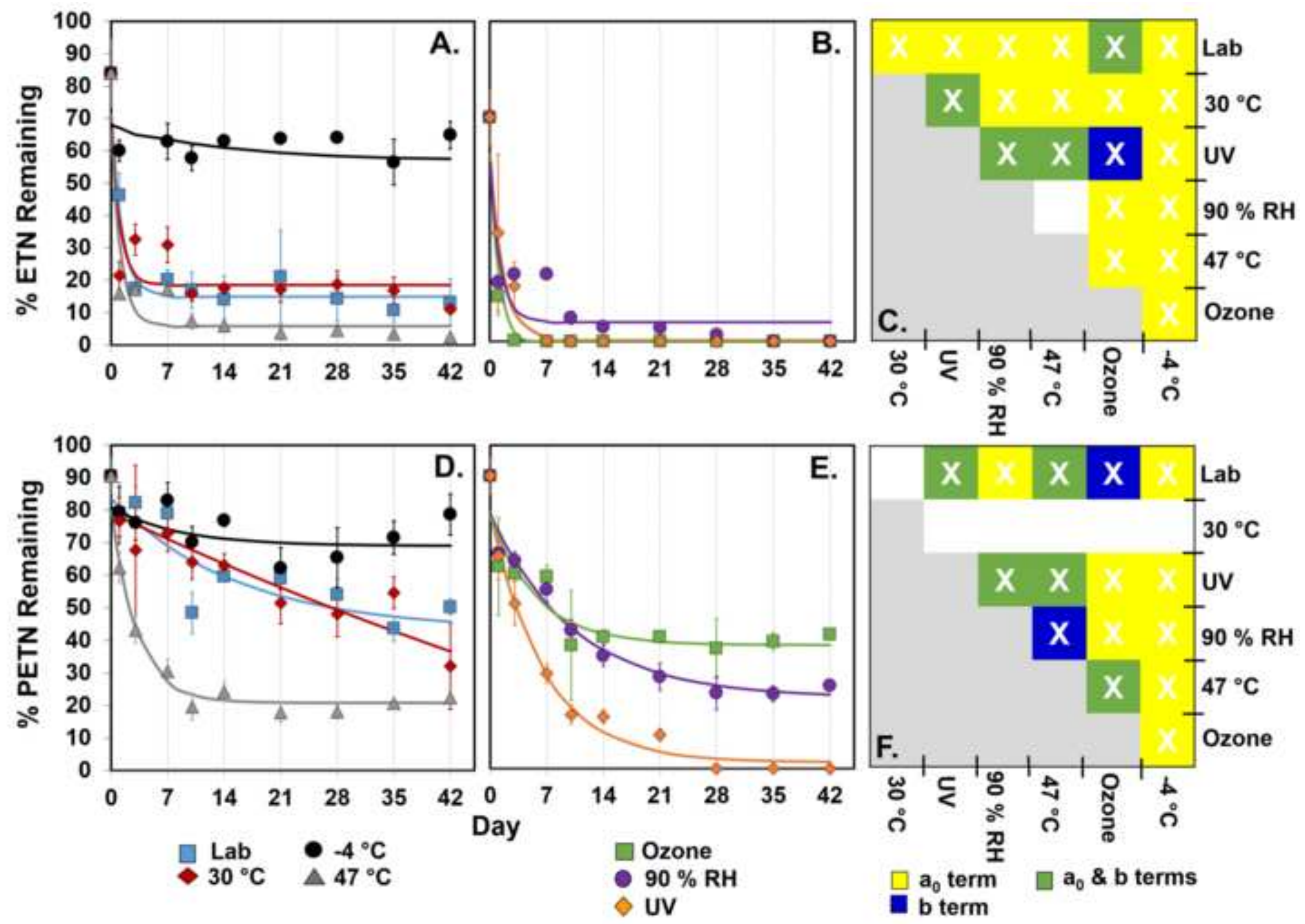



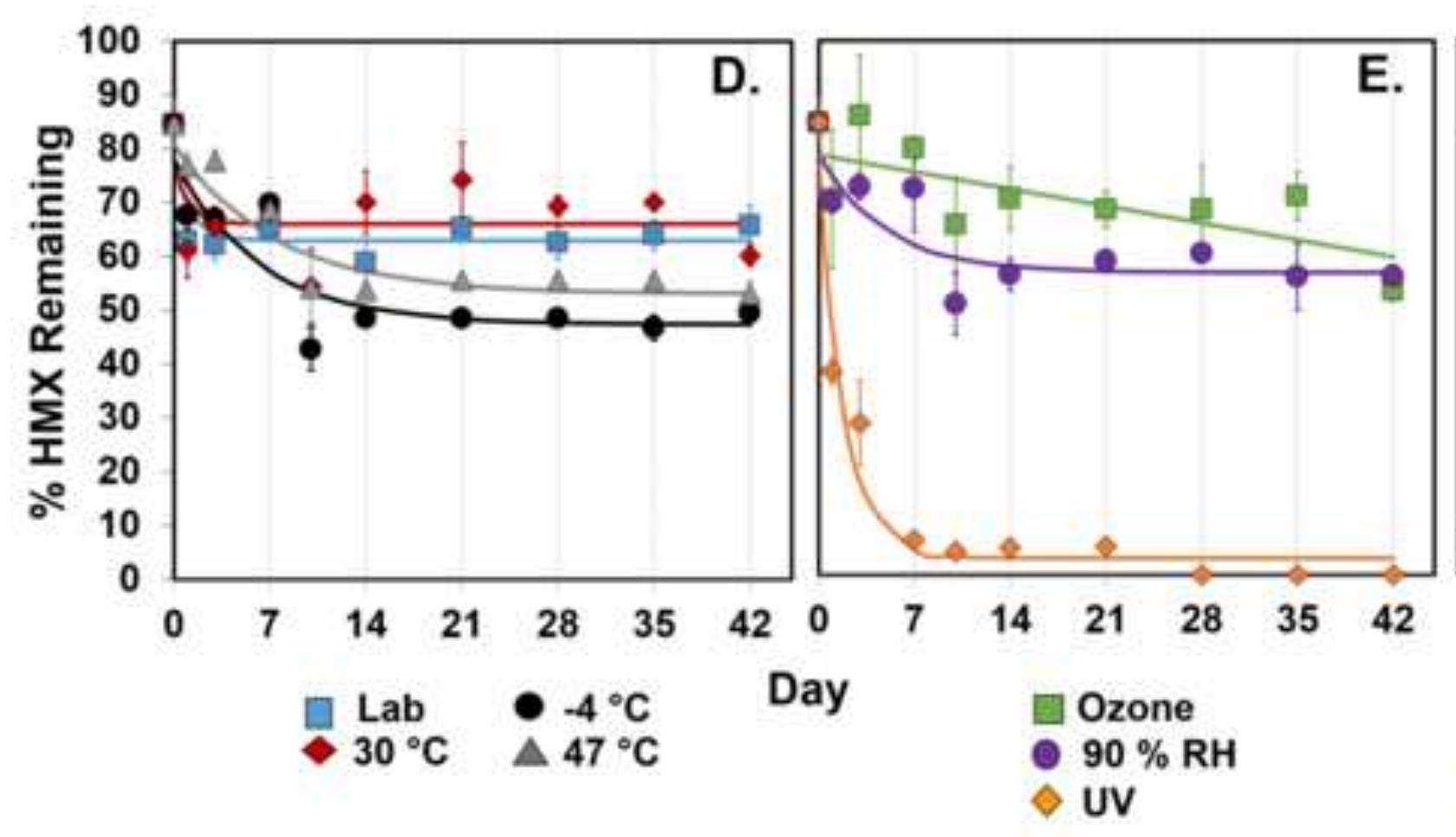

b term 

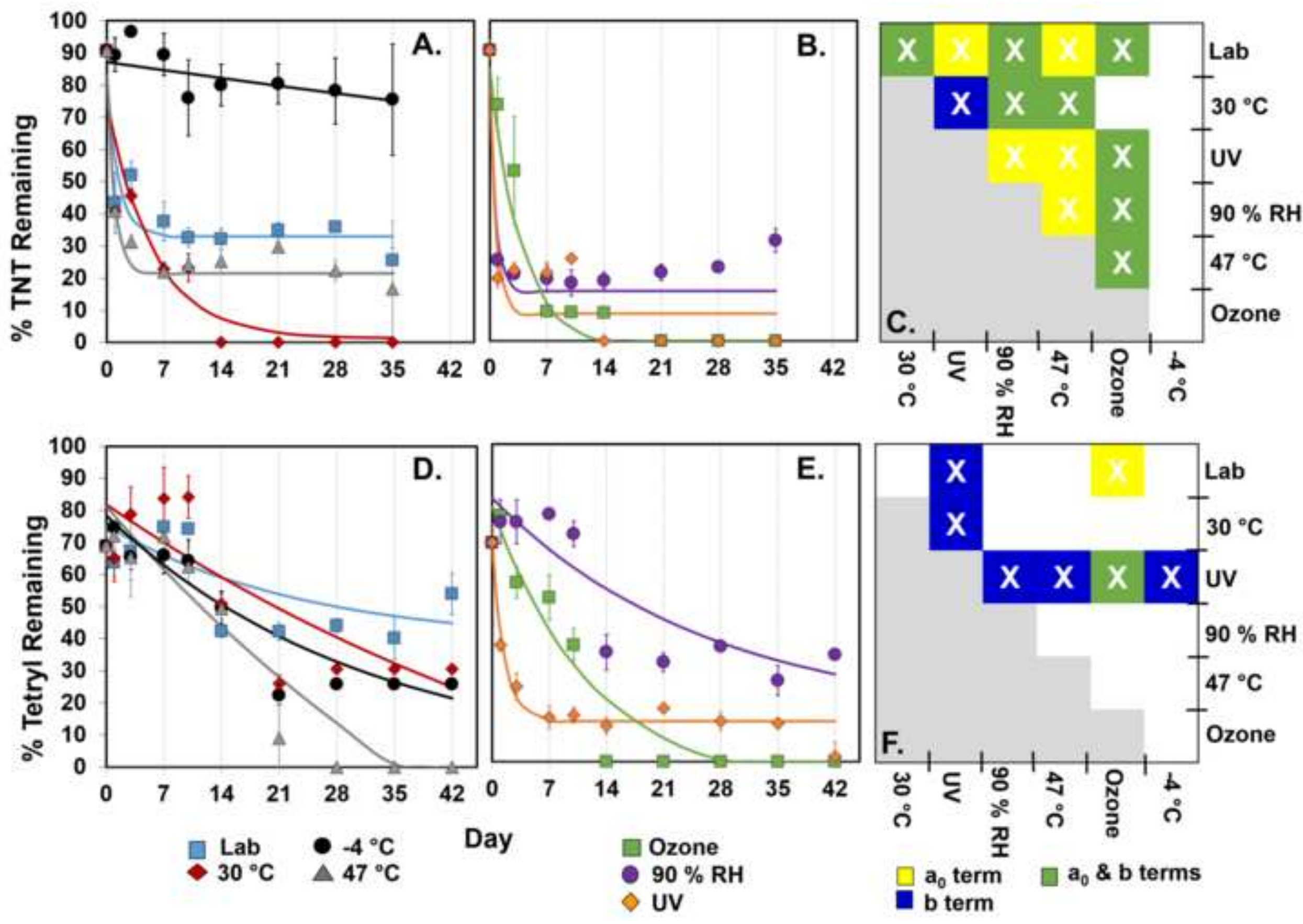